\title{
PENGEMBANGAN DIGITAL MARKETING DALAM MENINGKATKANDAYA SAING USAHA KECIL RAJUTAN TERDAMPAK COVID 19 DI KAMPOENG RAJOET KOTA BANDUNG
}

\author{
Yanti Susila Tresnawati ${ }^{1}$, Winne Wardiani ${ }^{2}$, Rini Anisyahrini ${ }^{3}$ \\ ${ }^{1,2,3)}$ Program Studi Ilmu Komunikasi, Fakultas Ilmu Sosial dan Ilmu Politik, Universitas \\ Pasundan Bandung \\ e-mail : yanti.susila@unpas.ac.id,winne.wardiani@unpas.ac.id, \\ rini.anisyahrini@unpas.ac.id
}

\begin{abstract}
Abstrak
Covid-19 berdampak negatif terhadap keberaadaan usaha mitra yang bergerak dalam usaha Rajutan, merupakan produk Unggulan Kota Bandung yang berada di wilayah Kampoeng Radjoet, Produk Mitra memiliki potensi untuk bersaing dengan produk sejenis baik dalam negeri maupun produk dari luar negeri. Akan tetapi masih dihadapkan pada Permasalahan yaitu belum Memahami, Memanfaatkan Dan Menerapkan Teknologi Informasi Pemasaran (Informasi melalui E-Commerce Web \& Apps dan Digital Marketing Content. Solusi yang ditawarkan : 1) Peningkatan Pemahaman Teknologi Informasi Pemasaran(Informasi melalui E-Commerce Web \& Apps dan digital marketing content. 2) Peningkatan kapasitas Teknologi Informasi berupa Laptop, dan Kamera sebagai sarana E-Commerce Web \& Apps dan Digital Marketing Content. Dan Merancang E-Commerce Web \& Apps. 3) Peningkatan Pemahaman dan Produksi Digital Content di E-Commerce Web \& Apps . 4) Peningkatan Pemahaman dan Pembuatan akun Official store di Marketplace, dan Peningkatan Pemahaman dan Pembuatan akun Official store di Video Streaming Platform (Youtube Channel). 5) Sinkronisasi keseluruhan akun dari mulai Web \& Mobile Apps sampe official store di semua platform digital (Facebook Pages,Instagram, Shopee, Youtube) dan Mitra Memanfaatkanya. Metode Kegiatan dengan menggunakan pendekatan : Pelatihan, Bimbingan teknis, Pendampingan, dan Fasilitasi. Dalam skema ini, Tim pengusul sebagai pelaksana kegiatan, yang memiliki tugas dalam menyelesaikan permasalahan dan mencapai solusi dan target luaran yang telah ditetapkan sesuai dengan kepakarannya serta melibatkan mahasiswa sebagai tim teknis. Hasil dan luaran yang telah dicapai dalam pelaksanaan kegiatan ; 1) Berubahnya Digital Maidset mitra, dan mampu memahami dari kemanfatan Teknologi Informasi (Digital marketing/ Distribusi) 2) Mitra Memiliki Fasilitas Teknologi Laptop 1 Unit (Asus TUF FX505DU), Kamera Sony Alpha 6300 KIT beserta kelengkapanya dan memiliki sarana teknologi informasi Web \& Apps 3) Meningkatnya Pemahaman Mitra, dan Penerapan: Produksi Digital Content, Distribusi Digital Content di E-Commerce Web \& Mobile, Memiliki akun Official store di Sosial Media,. 4) Mitra memahami dan memiliki akun Official store di Marketplace, akun Official store di Video Streaming Platform (Youtube Channel). 5) Sinkronisasi keseluruhan akun dari mulai Web \& Mobile Apps sampe official store di semua platform digital (Facebook Pages, Instagram, Marketplace, Youtube) dan Mitra Memanfaatkanya.
\end{abstract}

\section{Kata Kunci : Usaha Kecil, Digital Marketing, Daya Saing.}

\section{Abstract}

Covid-19 has a negative impact on the existence of business partners engaged in the Knitting business, which is the flagship product of the City of Bandung in the Kampoeng Radjoet region, Product Partners havethe potential to compete with similar products both domestically and abroad. But still faced with the problemthat is not yet Understanding, 
Utilizing and Implementing Marketing Information Technology (Information through E-Commerce Web \& Apps and Digital Marketing Content. Solutions offered: 1) Increased Understanding of Marketing Information Technology (Information through E-Commerce Web \& Apps and digital marketing content. 2) Increased capacity of Information Technology in the form of Laptops, and Cameras as a means of ECommerce Web \& Apps and Digital Marketing Content. And Designing E- Commerce Web \& Apps. 3) Increased Understanding and Production of Digital Content in ECommerce Web \& Apps. 4) Increased Understanding and Making Official Store Accounts in the Marketplace, and Increased Understanding and Making Official Store Accounts on the Video Streaming Platform (Youtube Channel). 5) Synchronize all accounts from Web \& Mobile Apps to official stores on all digital platforms (Facebook Pages,Instagram, Shopee, Youtube) and their Utilization Partners. Method of Activity using the approach: Training, Technical Guidance, Assistance, and Facilitation. In this scheme, the Proposal Team as the executor of the activity, which has the task of solving problems and achieving solutions and target outcomes that have been set in accordance with their expertise and involving students as a technical team. Results and outcomes achieved in the implementation of activities; 1) Changing partner Digital Maidset, and being able to understand from the benefits of Information Technology (Digital marketing / Distribution) 2) Partner Having a Laptop Technology Facility 1 Unit (Asus TUF FX505DU), Sony Alpha 6300 KIT Camera and its full range and having information technology tools Web \& Apps 3) Increased Partner Understanding, and Application: Digital Content Production, Digital Content Distributionon Web \& Mobile E-Commerce, Having an Official store account on Social Media ,. 4) Partners understandand have an Official store account on the Marketplace, an Official store account on the Video Streaming Platform (Youtube Channel). 5) Synchronize all accounts from the Web \& Mobile Apps to the official store on all digital platforms (Facebook Pages, Instagram, Marketplace, Youtube, and Utilizing Partners).

\section{Keywords: Small Business, Digital Marketing, Competitiveness.}

\section{PENDAHULUAN}

Dampak Covid19 menciptakan permasa lahan baru bagi pelaku usaha kecil sebagai berikut : Penjualan Menurun, Kesulitan Bahan Baku, Distribusi Terhambat, Kesulitan Permodalan dan Produksi Terhambat. Salah satu pelaku usaha Rajutan yang terdampak adalah para pelaku usaha di Kampoeng Rajoet Kota Bandung. (Sumber Data diolah, Agustus2020).

Usaha Kecil dalam perspektif ekonomi memainkan peranan yang sangat vital dalam pembangunan dan pertumbuhan ekonomi di negara sedang berkembang, dan negara maju. World Bank (2005) menyatakan bahwa, usaha kecil merupakan salah satu kekuatan pendorong terdepan dan pembangunan ekonomi yang amat vital dalam menciptakan pertumbuhan dan lapangan pekerjaan. Setidaknya terdapat tiga alasan yang mendasari negara berkembang belakangan ini, untuk memandang penting keberadaan usaha kecil (Berry,2001: 363), yaitu: Pertama, karena kinerja usaha kecil cenderung lebih baik dalam hal menghasilkan tenaga kerja yang produktif. Kedua, sebagai bagian dari dinamikanya, usaha kecil sering mencapai peningkatan produktivitasnya melaluiinvestasi dan perubahan teknologi. Ketiga, karena sering di yakini bahwa usaha kecil memiliki keunggulan dalam hal fleksibilitas ketimbang usaha besar.Melihat uraian dari kontribusi UMKM diatas begitu besar peranan yang diberikan terhadap pembangunan ekonomi Indonesia Dalam rangka upaya pembangunan ekonomi daerah, inventarisasi potensi wilayah/daerah,mutlak diperlukan agar dapat ditetapkan kebijakan pola pengembangan baik secara sektoral maupun secara multisektoral. Salah satu 
langkah inventarisasi/identifikasi potensi ekonomi daerah adalah dengan mengidentifikasi produk - produk potensial, andalan dan unggulan daerah pada tiaptiap sub sektor.

Undang - Undang Republik Indonesia, Nomor 20 Tahun 2008 : Bahwa Usaha Kecil merupakan kegiatan usaha yang mampu memperluas lapangan kerja dan memberikan pelayanan ekonomi secara luas kepada masyarakat, dan dapat berperan dalam proses pemerataan dan peningkatan pendapatan masyarakat, mendorong pertumbuhan ekonomi, dan berperan dalam mewujudkan stabilitas nasional. Meskipun usaha kecil telah menunjukan perananya dalam perekonomian nasional, namun masih menghadapi berbagai hambatan dan kendala baik yang bersifat internal maupun eksternal, Jafar (2004:41-43) menjelaskan, bahwa permasalahan yang dihadapi oleh usaha mikro kecil di Indonesia secara umum meliputi permasalahan, antara lain : 1. Masalah Internal (a. Kurangnya Permodalan, b. Sumber Daya Manusia (SDM) yang Terbatas, c. Lemahnya Jaringan Usaha dan Kemampuan Penetrasi Pasar). 2. Masalah Eksternal (a.Iklim Usaha yang Belum Sepenuhnya Kondusif (b. Terbatasnya Sarana dan rasarana Usaha, c. Implikasi Otonomi Daerah, d.Implikasi Perdagangan Bebas, e. Sifat Produk dengan Lifetime Pendek dan f. Terbatasnya Akses Pasar).

Sebuah produk dikatakan unggul jika memiliki daya saing sehingga mampu untuk menangkal produk pesaing di pasar domestik dan/atau menembus pasar ekspor (Sudarsono, 2001). Peranan produk unggulan sangat krusial karena merupakan produk yang mampu memberi kontribusi terbesar terhadap perolehan penerimaan daerah, terutama jika dilihat kontribusinya terhadap PAD-PDRB. (Darmawansyah, 2003).

Usaha Kecil Rajut merupakan Komoditas usaha unggulan Kota Bandung, Komoditas unggulan adalah komoditas yang memiliki keunggulan kompetitif, karena telah memenangkan persaingan dengan produk sejenis di daerah lain. Kriteria produk unggul, adalah komoditi yang memenuhi persyaratan kecukupan sumberdaya lokal, keterkaitan komoditas, posisi bersaing dan potensi bersaing. (Unkris Satya Wacana Salatiga).

Digital marketing menurut Urban (2004:2) adalah menggunakan internet dan teknologi informasi untuk memperluas dan meningkatkan fungsi marketing tradisional. Definisi ini berkonsentrasi pada seluruh marketing tradisional. Kita juga dapat menyatakan bahwa pendapat seperti "interactive marketing", one-to-one marketing dan "e-marketing" erat kaitannya dengan "digital marketing".Digital marketing menurut Ridwan Sanjaya \& Josua Tarigan (2009:47) adalah kegiatan marketing termasuk branding yang menggunakan berbagai media berbasis web seperti blog, website, e-mail, adwords, ataupun jejaring sosial. Tentu saja digital marketing bukan hanya berbicara tentangmarketing internet.

Mitra program dalam Program PPUD tahun ke 2 ini adalah Usaha Kecil Rajut yaitu Eka Rahmat Widjaya yang berlokasi di RW.05 Kelurahan Binong Jati, Kecamatan: Batununggal Kampoeng Rajoet Kota Bandung. Yang memulai usaha sejak tahun 2011san, yang bergerak dalam industri rajutan yang Menghasilkan produk Sweter, Syal, Kupluk, Pakaian Wanita dan lain - lain.

Alasan tim usaha ini dijadikan Mitra Kegiatan, karena merupakan salah satu objek yang pernah diteliti oleh Tim pengusul, Pertama: (Yanti Susila, 2014), Pengembangan Kompetensi Pemasaran Produk Rajut dalam Meningkatkan Keunggulan Bersaing Pada UKM Rajut Binong Jati Di Kota Bandung. https://scholar.google.com/citations. Kedua : Strategi Pengembangan Produk Unggulan berbasis One Vilage One Produk (OVOP) di Sentra Industri Kota Bandung https://scholar. google.co.id/citations (Dindin Abdurohim BS, 2008).

Produk Rajutan merupakan salah satu produk Unggulan dari 10 produk Unggulan Kota Bandung lainya, hal ini didukung oleh data sebagai berikut : 1) 
Hasil Penelitian Ina Primiana dkk (http://repository.unpad. ac.id/ 23 330/1/abstraklaporan-penelitian-Pemetaan- Kegiatan Ekonomi- Kota-Bandung.pdf) 2) Berdasarkan Surat Keputusan Walikota Bandung Nomor 530/ Kep.295DISKUMK. PERINDAG/2009,dan Ke 3) Surat Keterangan Usaha dari Kelurahan Setempat, Reg.No.187/ KT/SKU/BNG/ VIII/2018.

Dari hasil diskusi secara mendalam yang kami lakukan dengan mitra, diketahui bahwa Mitra kurang memiliki daya saing produk/Usaha. Selain itu permasalahan sering muncul sebagaimana halnya usaha kecil umumnya berkaitan dengan masalah internal dan maslaah ekternal, disamping itu Keberadaan Covid 19, Memberi dampak negatif terhadap keberadaan dan keberlanjutan usaha, maka tim dengan mitra memutuskan (justifikasi) dengan pertimbangan masalah yang harus segera dicarikan solusi karena menghambat stabilitas usaha, sebagai berikut:

1. Mitra belum Memahami, Memanfaatkan dan Menerapkan Teknologi Informasi dan Digital Marketing Content.

2. Mitra Juga Menghendaki adanya Digital Marketing Content. Seperti Adanya Foto, Video, Media Sosial Terkait Produknya, Bergabung Di Toko Online (Marketplace), Dan ada di Youtube Produk Atau Usahanya. Pencapaian tujuan dari program tersebut diharapkan dapat memberikan manfaat berupa Berkembangnya Usaha dan Daya Saing mitra sebagai Usaha Unggulan Kota Bandung.

\section{METODE}

Solusi yang ditawarkan :

Adapun Solusi yang ditawarkan dan dilaksanakan untuk menyelesaikan permasalahan Mitra sebagai berikut :

1. Peningkatan Pemahaman Teknologi Informasi Pemasaran (Informasi melalui ECommerce Web \& Apps dan digital marketing content).

2. Peningkatan kapasitas Teknologi Informasi berupa Laptop, dan Kamera sebagai sarana E-Commerce Web \& Apps dan Digital Marketing Content. Dan merancang E-Commerce Web \& Apps.

3. Peningkatan Pemahaman dan Produksi Digital Content di E-Commerce Web \&Apps

4. Peningkatan Pemahaman dan Pembuatan akun Official store di Marketplace, dan Peningkatan Pemahaman dan Pembuatan akun Official store di Video Streaming Platform (Youtube Channel).

5. Sinkronisasi keseluruhan akun dari mulai Web \& Mobile Apps sampe official store di semua platform digital (Facebook Pages,Instagram, Shopee, Youtube) dan Mitra Memanfaatkanya.

\section{Metode Pendekatan}

a. Metode Pelatihan

Metode pelatihan, ditujukan untuk mentrasfer lmu pengetahuan dan teknologi (Ipteks) dalam mengatasi permasalahan melalui peningkatkan wawasan, pemahaman bagimitra. Yang mana pelaksanaan pelatihan direncanakan dilaksanakan dalam satu ruangan di kampus Unpas. yaitu: Pelatihan Penerapan Teknologi Informasi Produk E-commerce Website \& Mobile Apps dan Digital Marketing Content, meliputi pelatihan : 1) Peningkatan Pengetahuan dan Penggunaan Perangkat dan Aplikasi Komputer pada Mitra 2) Peningkatan Pengetahuan dan Penggunaan Perangkat Kamera Profesional (Fotografi dan Videografi) 3)Peningkatan Pemahaman dan Skill Produksi dan Distribusi Digital Content,4)Peningkatan Pengetahuan dan pengelolaan Digital dan Sosial Media Marketing Strategy.

\section{b. Metode Bimbingan Teknis dan Pendampingan}

Metode Pendekatan ini, ditujukan untuk mentrasfer ipteks, agar mitra mampu mempraktekan hasil dari pendekatan pelatihan dengan Bimbin-gan Teknis dan 
Pendampingan dari pakarnya (tim), dimana metode pendekatan ini di laksanakan langsung di lapangan(tempat Mitra). Pakar/Tim bertindak secara aplikatif untuk mengarahkan, membimbing proses dantahapan, memberi contoh, yaitu : Pengelolaan $E$ commerce Web \& Mobile Apps, Praktek penggunaan perangkat kamera professional untuk produksi DigitalContent (Foto \& Video Produk), Praktek menggunggah hasil produksi Digital Content ke dalam E-commerce Website dan Mobile Apps, Prektek mengelola Digital \& Sosial Media Marketing Strategy padamitra.

\section{c. Metode Pendekatan Fasilitasi dan Media}

Metode pendekatan ini, ditujukan untuk mempermudah, meringankan, memperlancar, menghubungkan, membuatkan (mendesain), mendapatkan, dan memiliki sesuatu yangdibutuhkan oleh mitra. yaitu :

1. Fasilitasi Teknologi Informasi satu unit Laptop dan kelengkapanya untukpenerapanTeknologi Informasi.

2. Fasilitasi Digital Marketing Content, satu unit Kamera, Paket Lighting Mini Studio "Godox", Paket Background Mini Studio.

\section{Prosedur Kerja}

Untuk mendukung realisasi Metode yang ditawarkan, Tim Menerapakan prosedur sebagai berikut : 1) Melakukan Rapat Koordinasi pembagian tugas, dan koordinasi dengan Mitra 2) Menyusun Jadwal Kegiatan baik Tahapan Metode yang digunakan, menetapkan waktu dan kelengkapan/ peralatan, modul, tempat, yang harus disiapkan, baik untuk pelatihan, Bimbingan Teknis, Pendampingan dan Fasilitasi. 3) Merancang bahan evaluasi metode pendekatan yang digunakan. Pelaksanaan Program, mulai tahap persiapan sampai tahap evaluasi pelaksanaan, sedangkan tempat pelaksanaan di bagi dua untuk pelatihan dilaksanakan di kampus 1 Lengkong Besar dan pelaksanaan bimbingan teknis dan pendampingan di tempat mitra.

\section{HASIL DAN PEMBAHASAN}

Pelaksanaan kegiatan Pengabdian kepada Masyarakat melalui Pengembangan DigitalMarketing Pada usaha Kecil Rajutan Unggulan Rajutan Kota Bandung” telah dilaksanakan dari bulan Maret- Agustus 2020. Sampai saat ini sudah $100 \%$ terkait Solusi untuk Teknologi informasi dan digital Marketing. Dengan tahapan yaitu: Mulai dari Koordinasi kepada mitra mengenai kegiatan pengabdian secara keseluruhan serta penggunaan metode pelatihan, pendam- pingan, bimbingan teknis dan fasilitasi. Dalam pelaksanaan program dilapangan Mitra ikut berpartisipasi dalam menentukan waktu, dan tempat pelaksanaan.

Berikut adalah hasil dan luaran yang telah dicapai dalam pelaksanaan kegiatan PPPUD tahun ke 2 : Berubahnya Digital Maidset mitra, dan mampu memahami dari kemanfatan Teknologi Informasi (Digital marketing/ Distribusi), Hasil Pelatihan ini Mitra memahami bahwa Kemajuan teknologi telah membawa banyak perubahan padaperadaban manusia. Hal ini membawa trend baru dimana hampir semua orang selalu memanfaatkan teknologi seperti berkomunikasi melalui media sosial, berbelanja lewat e-commerce atau mencari tahu informasi lewat internet. Mitra mulai menyadari kekuatan yang muncul dibalik perkembangan teknologi Informasi ini,serta mitra memahami jenis - jenis digital marketing dan tujuan masing - masing seperti: SMS Marketing, E-mail Marketing, Search Engine Marketing, Social Media Marketing, dan Content Marketing. Mitra Memiliki Fasilitas Teknologi Laptop 1 Unit dan kelengkapanya (Asus TUF FX505DU) serta Kamera Sony Alpha 6300KIT dan kelengkapanya, dan memiliki sarana teknologi informasi E-Commerce Web \& Apps yang didalamnya berupa Alamat Web, Branding di laman awal web \& apps, 
Profil, Legalitas, Integrasi dengan jasa pengiriman \& system pembayaran, Fasilitas Fast Respons, Foto produk disertai ukuran dan 3Dimensi, Testimoni, WA Business, Google Maps : https://www. google.com/maps/place/Kampoeng+Rajoe t/. Berikut alamat Url Web Mitra : http:// kampungrajout31. wixsite. com/mysite.

Meningkatnya Pemahaman Mitra dan Penerapan: Produksi Digital Content, Distribusi Digital Content di E-Commerce Web \& Mobile, Memiliki akun Official store di Sosial Media. Berikut alamat akunt Mitra : Ig : kampoengradjoet.id, Fb. : https:// web.facebook.com/Kampoeng-Rajoet-. Disamping itu mitra mendapat fasilitas berupa ; Paket Lighting Mini Studio "Godox" dan Paket Background MiniStudio.

Mitra memahami dan memiliki akun Official store di Marketplace (Shopee,Tokopedia)https://www.google.com/search?source=univ\&tbm=isch\&q=ka mpoeng+rajoet, + sofiee \&safe=strict\&client=firefox, . Dan Shopee : galleraj.id akun Official store di Video Streaming Platform (You tube Channel: https://www.youtube. com.Sinkronisasi keseluruhan akun dari mulai Web \& Mobile Apps sampe official store di semua platform digital (Facebook Pages https://web.facebook.com/Kampoeng- Rajoet- 997326230339108/. Instagram, tokopedia: https:// www. tokopedia. com/kampoengrajoet, Youtube) _ https://www.youtube.com. dan dimanfaatkan oleh mitradalam digital marketing.

Hal penting dalam Pengembangan Digital Marketing Pada usaha Kecil Rajutan di Kampoeng rajoet Kota Bandung melalui program ini adalah pentingnya pemahaman semua pelaku usaha mengenai proses dan tahapan dalam Teknologi Informasi ECommerce dan Digital Marketing perlu menyeseuaikan dengan jenis usaha, dan target pasar. Pembelajaran lain adalah pentingnya perubahan pola pikir Maind Set dan perilaku khususnya Digital Maidset merupakan sudah keharusan untuk jaman sekarang atau Masa Industri 4.0 ini, dan terlebih adanya dampak Covid 19. setiap program penerapan Teknologi Informasi tidak akan berhasil. Pembelajaran selanjutnya adalah pengelola program harus senantiasa memiliki keluwesan atau fleksibel di dalam menjalankan program, mampu mendekati pemangku kepentingan dengan pendekatan kultural dan empati khususnya pada pelaku usaha kecil. Hasil program dalam bentuk hasil langsung atau keluaran (output), hasil tidak langsung (outcome) dan dampak sudah terasa bagi para penerima manfaat. Keberlangsungan program dapat terus dilaksanakan untuk meningkatkan Kontribusi Usaha Kecil kepada Berbagi Pihak.

\section{SIMPULAN}

Pelaksanaan program pengabdian kepada masyarakat melalui Pengembangan Digital Marketing dalam Meningkatkan Daya Saing Usaha Kecil Rajutan Di Kampoeng Rajuet Kota Bandung pada mitra memberikan dampak positif bagi pelaksanaan program, terlihat sesuai tujuan Program yaitu: 1) Berubahnya Digital Maidset mitra, dan mampu memahami dari kemanfatan Teknologi Informasi (Digital marketing/ Distribusi). 2) Mitra Memiliki Fasilitas Teknologi Laptop 1 Unit (Asus TUF FX505DU), Kamera Sony Alpha 6300 KIT beserta kelengkapanya dan memiliki sarana teknologi informasi Web \& Apps. 3) Meningkatnya Pemahaman Mitra, dan Penerapan: Produksi Digital Content, Distribusi Digital Content di E-Commerce Web \& Mobile, Memiliki akun Official store di Sosial media,. 4) Mitra memahami dan memiliki akun Official store di Marketplace, akun Official store di Video Streaming Platform (Youtube Channel). 5) Sinkronisasi keseluruhan akun dari mulai Web \& Mobile Apps sampe official store di semua platform digital (Facebook Pages, Instagram, Market- place, Youtube, dan Mitra Memanfaat-kanya. Hal pentingdalam Pengembangan Digital Marketing Pada usaha Kecil Rajutan di Kampoeng rajoet Kota 
Bandung, melalui program ini adalah pentingnya pemahaman semua pelaku usaha mengenai proses dan tahapan dalam teknologi Informasi E-Commerce dan Digital Marketing perlu menyeseuaikan dengan jenis usaha, dan target pasar. Pembelajaran lain adalah pentingnya perubahan pola pikir Maind Set dan perilaku khususnya Digital Maidset merupakan sudah keharusan untuk jaman sekarang atau Masa Industri 4.0 ini dan terlebih adanya dampak Covid 19.

\section{DAFTAR PUSTAKA}

Abdurohim, Dindin. (2020). Pengembangan Kapasitas Kelembagaan UKM. Yogyakarta, Bintang Madani,

Abdurohim, Dindin, 2020. Pengembangan Kapasitas Kewirausahaan dan Desiminasi Teknologi PadaKelompok Usaha Kecil di Kertasari Kabupaten Bandung.

Abdurohim, Dindin, 2020. Pengembangan Daya Saing Usaha Kecil Unggulan Kota Bandung. Jurnal Pengabdian Kepada Masyarakat. Uninus.

Abdurohim, Dindin, 2019. Conference Proceeding Of One AsiaCommunity.

Abdurohim, Dindin, 2017. Disertasi : Pengembangan Usaha Kecil Studi Kasus pada Usaha kecil Konfeksi di Kota Bandung.

Abdurohim, Dindin, 2008, Strategi Pengembangan Produk Unggulan berbasis One Vilage One Produk (OVOP) di Sentra Industri Kota Bandung, Penelitian kerjasama Unpas dengan Dinas Perindustrian dan Perdagangan Kota Bandung.

Berry, A. E. Rodriques, dan H. Sandeem, 2001.Small and Medium Enterprises Dynamics in Indonesia. Bulletin of Indonesian Economics Studies 37(3):363384.

Darmawansyah.2003.Pengembangan Komo - diti Unggulan Sebagai Basis Ekonomi Daerah. Tesis S-2 Program PascaSarjana IPB. Bogor.

Hafsah, Mohammad Jafar. 2004. Upaya Pengembangan Usaha Kecil Menengah. Infokop No. 25 Tahun XX. http://jurnal. smecda. com / index.php/infokop/article/view/60/57.

Sudarsono, 2001. Konsep Ekonomi: Uang danBank. Rineka Cipta: Jakarta.

Yanti Susila, 2014, Pengembangan Kom- petensi Pemasaran Produk Rajut Dalam Meningkatkan Keunggulan Bersaing Pada UKM Rajut Binong Jati Di Kota Bandung. Penelitian Hibah DRPM Kemenristek Dikti.

Yanti Susila Tresnawati, Rudi Martiawan,Dindin Abdurohim, 2018. Pengemban -gan Kapasitas Usaha Kecil Syal KotaBandung.Jurnal Pengabdian Kepada Masyarakat,Vol8,No 2 (2018),http://103.66.199.204/index.php/JPK M/article/view/278.

Yanti Susila \& Dindin Abdurohim, 2018. SME's development indicators and organizational capability, Article in Human Systems Management 37(2):249-253.

Berbagai Sumber Website /Seputar UMKM Kota Bandung/ yang di Olah, 2015 20197. Searching, Maret-Mei 2019.

Dinas Koperasi UKM dan Industri Perdagangan Kota Bandung, 2018

DRPM. Kemenristek Dikti RI, 2018, Panduan Pelaksanaan Penelitian dan Pengabdian Kepada Masyarakat, EdisiXII. 2018. http://repository.umy.ac.id/bitstream/handle/ Ina Primiana dkk (http://repository. unpad. ac. id/23330/1/abstrak-laporanpenelitian-Pemetaan-Kegiatan Ekonomi-Kota- Bandungpdf)

Peraturan Menteri Dalam Negeri Nomor 9 Tahun 2014. Tentang Pedoman Pengembangan Produk UnggulanDaerah. RPJMD Kota Bandung 2014-2018.

Sanjaya, Ridwan dan Josua Tarigan, 2009. Creative Digital Marketing. PT Elex Media Komputindo. Jakarta.

Surat Keputusan Walikota Bandung Nomor 530/Kep.295-DISKUMK.PERINDAG 
12009, dan Ke 3) Surat Keterangan Usaha dari Kelurahan Setempat, Reg.No187/KT/SKU/BNG/VIII/2018.

Surat Keputusan Menteri Keuangan (Menkeu) No.316/KMK.016/1994. SK tersebut mewajibkan Badan Usaha Milik Negara (BUMN) untuk menyisihkan 1-5\% laba perusahaan bagi Pembinaan Usaha Kecil dan Koperasi (PUKK).

Surat Keterangan Usaha dari Kelurahan Setempat, Reg.No.187/KT/SKU/BNG/ VIII/2018.

Undang - Undang, 2008. Undang - Undang Rebuplik Indonesia No. 20 tahun 2008 Tanggal juli 2008 tentang Usaha Mikro, kecil, dan Menengah.

Urban, Glen (2004) Digital MarketingStrategy.Pearson Educattion, Upper Saddie River, New Jersey. USA 